\title{
Migration among Farmers in Delta State, Nigeria: Is it a Climate Change Adaptation Strategy?
}

\section{Albert Ofuoku ( $\nabla$ albertofuoku@gmail.com )}

Delta State University, Asaba Campus, Asaba, Delta State, Nigeria https://orcid.org/0000-0003-13958114

\section{Davina Okompu}

Delta State University

\section{Article}

Keywords: Adaptation strategies, agricultural extension services, climate change, climate extension services, climate change mitigation, internal migration

Posted Date: October 14th, 2020

DOl: https://doi.org/10.21203/rs.3.rs-90384/v1

License: (9) This work is licensed under a Creative Commons Attribution 4.0 International License. Read Full License 


\section{Abstract}

Objective: The study has the purpose of evaluating the nexus between climate change and migration of farmers in Delta State, Nigeria. The influence exerted by cognitive situations and climate - driven stress on farmers' decisions to migrate and the socioeconomic attributes of migrating and non-migrating farm families are examined. The emphasis is the function of migration in accessing climate and agricultural extension services as well as the contribution made by migration to promote farmers' climate change coping capacity.

Methodology: Survey was articulated using farming households in three agricultural zones of Delta State, Nigeria. Perceptions of farmers about alterations in climate were examined with the use of mental map technique. Binary logistic regression model was applied to assess the function of socioeconomic attributes of farm families while descriptive statistics was employed in evaluating the adaptive capacities of the migrating farming households.

Findings: Climate - driven livelihood variables form part of the main propellers of migration among farmers. Migration as well as the socioeconomic attributes are influenced by perception of farmers about climate change. These appears significant difference between migrating and non-migrating farm families with respect to utilization of information, technology and knowledge emanating from agricultural and climate extension services. The gains from remittances, knowledge and social networks from host communities or zones raises migrating farm families capacity to adapt to climate change.

Theoretical Implications: This paper contributes to the progressively dynamic body of knowledge by pointing out migration as an alternative climate change adaptation strategy to promote agriculture food security in any part of the world.

Originality/Value: Micro - evidence is offered by this study with respect to contribution made by migration to adaptive capacity of farmers and their ability to have access to agricultural and climate extension services. This will be useful in the analysis of climate - driven migration in other nations that are agricultural economies. Insight is also offered regarding policy needs for the scaling down of farmers' vulnerability to climate change.

\section{Introduction}

Movement of people prompted by environmental threats is an age long phenomenon. Livingstone (2000) suggests that Hippocrates and Aristotle were of the belief that the attributes of natural environment are determinants of human habitability of a location, as well as the qualities of the humans that inhabit it. Increase in the rate of rural-urban migration is a consequence of wide differences in income levels and standards of living in developing nations like Nigeria. Harris and Todaro (1970), Lucas (1997), and Stark (1984) have offered theoretical support for this hypothesis of internal migration. Internal migration is vertically and horizontally articulated by Fei and Ranis (1964) as a process that is desirable, through which surplus labour is taken from agricultural occupations and moved to offer cheap labour or 
manpower for modern industrial state. According to Kohli et al (2011), a nation is most likely to remain in middle income trap, should such a nation fail to create transition from labour - intensive to capital intensive production.

Agriculture is highly dependent on climate factors as it is a climate - sensitive sector that harbours increased labour surplus and it has become one of the contributory factors of internal migration to sectors that are non-climate - sensitive. The model of economic development of Harris and Todaro (1970) articulates some propellers of rural-urban migration. The fundamental postulation is that migration is prompted by the differential income of rural and urban settlements that is expected as well as wage difference. Lucas (1997) supports this model, however, he went further to opine that comprehension of the pull factors which determine the urban side apart from wage differential continues to be poor. To buttress this, De Haas (2020) notes that occurrence of migration is significantly dependent on the skill and knowledge level of the migrants as well as the prevailing conditions in the particular economic sectors where they hope to secure employment at home and at the destination.

In concept, the new economics of labour migration (NELM) models are different from other models because they incorporate rural risk factor as a determinant of decisions to migrate (Jha et al., 2018). This approach implies that decision to migrate an affairs of families and households instead of that of the lone individual (Jha et al., 2018); Stark and Lucas, 1988; Stark and Bloom, 1985). The NELM model likewise considers migration as a strategy created by a family or household to maximize expected incomes and reduce risk of failure in consumption by engaging in diversified sources of income by crossing sectors or agricultural zones.

Migration of humans is not only necessitated by poverty and social deprivation, but it is as well prompted by climate change (Scheffran et al., 2012; Ofuoku and Chukwuji, 2012). Unfriendly weather conditions, rise in sea level and environmental degradation constitute the important outcome climate change. The alterations are the main causes of long - or short - term migration as a result of loss of occupations that are sensitive to climate and poor capacity to adapt to the situation in South Asia (Bhatta and Aggarwa 2016; Kumar and Viswanathan, 2012) and in sub-Sahara Africa, including Nigeria (Ofuoku et al., 2011). As also suggested by Ahmed et al., (2016); Barnett and Webber (2009) suggest that households capacity to adapt to climate change depends on diverse factors, which include financial base, social resources, infrastructure, human capital and access to information. To be resilient or be able to adapt, Gray and Mueller (2012) opine that farming households will probably cut down expenditures on goods that are non-essential, access formal and informal credit or depend on assistance from governments. On the alternative, or in combination with one or more of the earlier suggestions, farming household may decide to allow a member of the household to move to other locations to engage in alternative sources of income, which is remitted to the household or origin (McLeman and Smith, 2006; Ofuoku, 2017). When or where group - based mitigation activities and spatial coping methods are not on ground, migration becomes a very important climate change adaptation strategy for farming households against the shocks that accompany it (JTha et al., 2018). Shatta et al., (2015) explain that owing to uncertainty surrounding climate - sensitive livelihood activities, farming households embark on diversification of 
livelihood, which is an important strategy for several economic and environmental constrains. Banerjee et al., (2011) emphasize that remittances are the most glaring factor that enhance farming households' capacities to adapt to conditions of stress. Enhanced income from diversification of sources of livelihood creates room for farming household to increase their capacity to adapt in order to cope with the risk accompanying climate change (Patnaik and Das, 2017; Tripathi 2017; Scheffran et al. (2012), Tacoli (2009), Larzko and Aghazarm (2009) and Ofuoku (2019) states that in order to avoid the disastrous consequences of climate change adaptations has been made a very significant policy option and that one of the adaptation strategies of potent is migration. Since agriculture is the most climate - centered economic activity, it is faced with the highest risk and uncertainties that lead to loss of livelihood. At the national level, farmers first identify or observe alteration in climatic parameters and take to migration as a coping strategy (Stojanov et al, 2016a, 2016b). At the farm level, farmers constitute the major stakeholders and actors, thus their perceptions about climate change and their socioeconomic attributes, especially of their households, form the major factors propelling their migration. The socioeconomic situations are determinants of the level of vulnerability of farming households to climate - induced economic challenges and social deprivation in spite of the fact that their perception of climate change constitutes a prerequisite for the individual farmer's adaptation reaction (Jha et al, 2018). Farmers tend to choose to migrate to seek alternative means of livelihood in a situation of risk of crop failure or poor yield owing to the effect of erratic climate outcomes. Migration offers the farmers opportunities to gain knowledge on new technologies and techniques and farm practices to increase their agricultural income as well as enable them to generate defined expected income. Apart from that, the remittances made from hose community or zone lowers credit related challenges adaptation strategies adaptation (Patnaik and Narayanan, 2015), thereby enhancing the adaptive and resilience capacities of the home zone.

Having articulated this theoretical background, it is worthwhile to carry out a study on the nexus between migration and climate change in a close context specific way through integration of diverse socioeconomic, cultural, political and developmental variables. There is also the need to unveil the way farmers household qualities exert influences on decision to migrate in order to create better informal zonal or regional policies (Upadhyay et al., 2015). This study develops a comprehension of the role played by migration as a strategy for adaptation for coping with climate alteration as well as attempt to change the course of the argument that "migration is not at all times the consequence of failure of an individual farmer to adapt effectively to climate change". It examines the perception of farmers on climate/weather changes and in accordance unveils various cognitive situations that induce farmer's migration decision during rainy or dry season. Also, the socioeconomic situations of migrating and nonmigrating farming households were assessed. The emphasis of this study is to assess the role played by migration in accessing climate and agricultural extension services. It went further to evaluate the contribution made by migration to enhancement of farmer's coping capacity.

\section{Literature And Theory}

Climate change according to Warner and Afifi (2014), Gray and Bilsborrow (2013), Hunter et al., (2013), Muckere et al (2014) is a stress variable that has a major under - tone for migration in regions that are 
vulnerable to climate alterations. Klaiber (2014) suggests that migration offers farmers the opportunity to carry out non-margin shifts in arrangement of adapting to alteration in climate, while Warner (2010) states that the effects of climate variation on migration have for many years been a subject matter of great interest among policy makers and academics.

The fundamental postulation that inundates literature is that farmers migrate to other communities because they could not succeed to adapt to climate change in an effective manner (Warner, 2010). Environmental factors, Porter et al., (2014) states has indirect effect on farmer's decision to migrate through its impact on livelihood activity, for instance agricultural productivity los and hiked expenditure as a result of rising prices of food. Lybbert and Sumner (2012) are of the view that sources of credit may not be enough for adaption of modern technologies needed for adaptation and change mitigation of climate change. In most sub-Sahara, (Ofuoku et al., 2012) and South Asian countries, the likelihood of migrating during adverse environmental situations is more among farming households that have poor socioeconomic background (Bhatta et al., 2015a; Bhattaet al. 2015b; Etzold et al., 2014). Decisions related to migration are rooted in the individual farmers' vulnerability in terms of economic, social, demographic and political factors (Yi Sun et al., 2017; Stojanovet al, 2016a; Stojanov et al., 2016b). Individual members of farm families are probably relocated in order to generate income for the sustenance of the family expenditures, achieve knowledge and enhance capabilities for surmounting shocks and stresses in the future (de Hann et al., 2002).

\subsection{Rationale for migration}

Migration is capable source of transfer of capital to aid traditional or local communities to progress towards elitist knowledge and education (Taylor, 1999). For example, in developing countries, agricultural extension is a crucial mechanism of knowledge, innovation or technology and education for farm families (Rivera and Sulaiman, 2009). Swanson (2006) describes agricultural extension services as the all-encompassing institutional arrangements that are meant to aid farmers organize themselves and create linkages between farmers and markets. Transfer of resources acquired to home location or zone, such as remittances, return of migrant and knowledge make immense contributions to enhance level of awareness of the work of institution and technical sources of agricultural extension services and climate information services (Jha et al., 2018). Income remitted home has direct effect on the resource base, economic welfare and resilience of the migrant source community (Adger, et al. 2002). Capabilities of the source community to achieve development and sustained livelihood is enhanced or propped up by individual migrants from the community. In most developing countries, high rate of migration has prompted substantial increase in income emanating from remittances. There is the need to give strength to the linkages between host and source communities in other to reactively strengthen home community resilience (Conway and Cohen, 1998), enhance its economic well - being (Adger et al, 2002) and offer access to needed resources required to enrich its human, cultural and social capital (Woodrugg and Zenteno, 2007). Social relationships in the host community have likewise been indicated as a crucial factor to employment and opportunities to shelter (Ofuoku, 2019). 


\subsection{Migration caused by climate change}

Since in the prehistoric era there have been linkages between human migration and settlements as indicated by a wide range of literature (Jyson et al., 2002). While responding to loss of occupations that are climate sensitive and the ones that are not climate sensitive, citizens of communities decided and actually diversified their sources of livelihood through intensification of farming and non-farming activities (McDowell and Haan, 1997). More emphasis was put by Tschakert and Tutu (2010) on the value of migration while coping with climatic alterations. Bhatta and Agarwal (2016) observe that an enormous population of marginal and landless farmers in South Asia migrated in the bid to cope with climate change and variability. Climate change impacts on dynamics of human migration vary much of note in rural settlements because the people do not have adaptive capacity (Kates, 2000). The way individuals perceive climate change is a valuable precondition for their adaptation (Gbetibouo, 2009; Bryan et al 2009, Hassan and Nhemachena, 2008). At the household level, climate induced decisions to migrate among farm families are driven by their perception about climate change and variability, the risk linked with it and probabilities of crop failure and loss of source of livelihood as well as the necessity of having alternative sources of income. The decision of farmer to embark on migration goes through a course of cognition which entails remembrance of previous climate aberration incidents and the represent time comprehension of the climate rooted on intuitive knowledge as well as perceptions about risks linked with climate change (Grothmann and Patt, 2005; Marx et al 2007, Adger et al, 2009). However, Hausen et al (2004) opine that in the presence of the significant variations that exist between individual experience and external information sources, owing to climate variability, farmers are likely to place more value on current climatic occurrences. Indecisiveness may likewise be prompted by broader differences between farmers' expectations on climate variations and actual climate forecasts given by the agency incharge (Below et al, 2010; Roncoliet al., 2002). Alterations in agricultural systems do not entail straight line update of an individual farmer's decision making, thus the way farmers review their climate variation anticipation importantly becomes a determinant of his or her decision regarding adaptation (Bryan et al., 2009; Gbetibouo, 2009).

Aggregate migration flow stands for the consequence of the underlying individual decision - making process. Migration being a human behavior is, thus a complementary approach more than an alternative approach. Right thinking individuals tend to maximize their anticipated utility function, as a result, the decision whether to migrate or not is determined by the cost - benefit analysis. Hicks (1932) argued that maximizing behavior is born out of differences in net economic advantages. The gains of migration are the main causes of migration. Inspite of the catalogue of literature on climate change and variability, adaptation and migration, there are still gaps in unveiling the ongoing heterogeneous influences in the home of origin that propel migration and the way migration go on to promote the ability of the migrating household member to gain knowledge on management of farm and benefits of extension services. There are limited studies on climate - induced patterns of migration among various heterogeneous groups (Bhattaet al. 2015b), in Nigeria. It is thus a matter of necessity to comprehend how migration is the main source of resilience of household in climate change situation or scenario. 


\section{Methodology}

\subsection{The Study Area}

The study was carried out in the three agricultural zones of Delta State, Nigeria. The agricultural zones are demarcated according to the ecological zones of the state. The agricultural zones include Delta North, Delta Central and Delta South Agricultural Zones. Delta North Agricultural Zone lies majorly under the derived Savannah vegetation cover; Delta Central Agricultural Zone is covered by fresh water and rainforest, while Delta South Agricultural Zone is under mainly mangrove swamp forests cover. Delta State experiences drought two distinct seasons - the raining season which commences in April and terminates in October in Delta Central Agricultural Zone. In the Delta South Agricultural Zone, raining season begins in March and ends in November, while rains start falling in Delta North Agricultural Zone in the month of May and terminates in August. While Delta Central does not experience much of drought, there is the period of drought and flooding is being experience for some years now. The level of flooding in Delta South Agricultural Zone has increase, with moisture still being present in the soil during dry season. However, much of drought is experienced in Delta North Agricultural Zone during the dry period (November to April). Two farming seasons exist in Delta State, early cropping season (April) and late farming season (September).

Delta State is located in Southern Nigeria with the River Niger. Delta lies in the coordinate of longitude $5^{0}$ $50^{`}$ and $6^{\circ} 45^{`}$ east of the Greenwich meridian and latitudes $5^{\circ}, 25^{`}$ and $6^{0} 30^{\circ}$. The state is predominantly rural with about $80 \%$ of the population found in the rural areas. Internal migration is known to occur regularly, however, there is no official record of internal migration as such records are not in existence and no agency has been put in place to take care of that issue. Internal migration is highly implicated in the economy of the state and Nigeria at large. Deltans are one of the most mobile people after the Ibo tribe in Eastern Nigeria.

\subsection{Sampling and Sample Size}

Delta North Agricultural Zone is constituted by 9 local government areas. Delta Central Agricultural Zone is made up of 10 local government areas, while Delta South Agricultural Zone houses 6 local government areas. From each zone, $50 \%$ of the local governments were selected. Consequently in Delta North 5; Delta Central 5 and Delta South 3 local government areas were randomly selected. Three rural communities were randomly selected from each of the 13 local government areas selected. The heads of the villages were met for identification of the full-time farmers. This exercise led to identification of 7,226 farming households. Ten percent (10\%) of the farmers were randomly selected and 723 respondents were arrived at. At the end the enumerators used to collect data from the farmers were able to return complete data from 698 farming households. The study involved every class of farmers in terms of farm size-small, medium and large.

\subsection{Design of the Questionnaire}


The issues relating to the questionnaire were discussed with the farming household heads (FHHs) to make sure that they are answered as accurate as possible and data were collected. The selected FHHs belonged to various land ownership strategies (that is, either farming on own land or rented land). The questionnaire captured local perception of the farmers as well as their observation about climate change and their experiences with variation in climate and extreme occurrences for the period of over the past two decades. Mental map technique (MMT) was also applied. In the MMT, the farmers were requested to give their local perceptions about alterations in climate based on their experiences and observations of alterations/variations in climate parameters. Ethnographic studies have the confirmation that persons are capable of identifying change in climate a decade or more on the basis of his or her own experience (Ofuoku and Albert, 2014; Marin, 2010). A previous study by Ofuoke et al (2012) saw through the lenses of the farmers and found that the farmers identified alterations in climate parameters such as rainfall and temperature for over a period of 30 years. The questionnaire also had questions on the FHHs socioeconomic situations, as well as the choices of information on climatic issues and new agricultural innovations (agricultural extension and climate). Their access to these information and the innovations were also captured. Their adaptation strategies choices among a list of diverse adaptation options for the rainy and dry seasons separately. The adaptation alternatives included capital - intensive, labour intensive and knowledge - intensive innovations for the facilitation of the assessment of contribution status of migration to adaptation measures adopted.

\subsection{Analysis of Data}

While assessing the role played by socioeconomic attributes of the $\mathrm{FHHs}$, binary logistic regression model was applied. The study was rooted majorly on an assumption that decisions by farmers to migrate are strategies of the family hence, if the farmers does not embark on migration one or more members of the farm family is made to migrate to a location that is close or a distant urban settlement. In the study behavioural qualities of migrating and non-migrating farm families were utilized. No psychological factor apart from perceptions about climate - induced stress as a propeller or pushing force of migration of farmers. Descriptive statistics were useful in unveiling the variations in adaptation behavior, choice of climate extension and agricultural services and the pattern followed in adoption of various adaptation methods between migrating and non-migrating farming households.

\section{Results And Discussion}

\subsection{Farmers' Perception about Climate and Migration}

The shape of migration (temporary or permanent) is determined by the farmers' perception and experiences of climate extremities and variability. A farmer has more likelihood of migrating permanently as a consequence of continued loss of losses, livelihood and wealth when he or she faced high level of vulnerability to climate extremities and continual experience of alterations in patterns of climate. Then the farmers who experience the effects of seasonal variations in climate and temporary climate alterations will likely have the decisions to create temporary income generation to meet up with livelihood 
needs. The climate parameters put into consideration in this study included temperature and rainfall. The perceptions of the farmers about climate change were assessed on the basis of dichotomous responses (yes or no) to the question of whether they observed long term variations or alterations in average levels of temperature and rainfall since the past 20years or more. The farmers' decision to migrate was evaluated for the two existing farming seasons - early farming and late farming seasons owing to climatic conditions that are ideal for crop yield level and consequently, farm cost of production and management practices vary according to farming season. Rooted in the farmers' responses to questions perception of alteration in temperature and rainfall as well as their options to embark on migration because of sensitivity of crops, Jha et al (2018) four cognitive situations of farmers were put into consideration. These included:

i. Perceived changes in climate and migrate;

ii. Perceived changes in climate but do not migrate;

iii. Do not perceive changes in climate and hence do not migrate; and

iv. Do not perceive changes in climate, but choose to migrate.

Table 1 shows that about $65 \%$ chose to migrate, while about $35 \%$ chose not to migrate during the early farming season. During the late farming season, $68 \%$ chose to migrate, while $32 \%$ opted not to migrate. Going further, with respect to crops sensitivity to alterations in rainfall patterns, $63 \%$ and $37 \%$ chose to migrate and not migrate, respectively during the early farming season. During the late cropping season, about $70 \%$ chose to embark on migration, while $29 \%$ opted out of migration. During the two seasons, the number of farmers who opted to embark on migration as a consequence of perceived climatic alterations was much higher than the ones who chose to migrateinspiteof the fact that they did not perceive climate change and variability. However, a good percentage $(20-35 \%)$ of them perceived alterations in climate pattern, but refuse to migrate. These differences in option decision are attributable to qualities of the farming households farm families. These findings are in consonance with those of Jha (2018).

Migration was seen as a profitable coping strategy by most of the farmers used for the survey. Perception of climate change and migration formed the dominating cognition situation for early cropping and late cropping seasons in Delta State.

\section{Table 1: Perceptions on Climate Change Variability as Propellers of Farmers' Migration decision}




\begin{tabular}{|lllll|}
\hline Conditions & \multicolumn{2}{l|}{$\begin{array}{l}\text { Early farming season } \\
\text { Temperature Rainfall }\end{array}$} & $\begin{array}{l}\text { Late farming season } \\
\text { Temperature Rainfall }\end{array}$ \\
\hline Migrated total & 65 & 63 & 68 & 71 \\
\hline Did not migrate & 35 & 37 & 32 & 29 \\
\hline Perceived and migrated & 59 & 56 & 61 & 62 \\
\hline Did not perceived but migrated & 6 & 7 & 7 & 9 \\
\hline Perceived but not migrated & 31 & 31 & 28 & 25 \\
\hline Did not perceive and not migrated & 4 & 6 & 4 & 3 \\
\hline
\end{tabular}

NB: The figures are in percentages, but some may not round upt to 100 as a result of rounding off.

This situation is majorly rural risk factors have association with climate alterations and variations in their home community or zone. The decision to embark on migration is one of the farm household coping mechanisms and not the decision taken by an individual. Farmers who fell under the second cognitive situation (migrating when they did not perceive climate change), did so mostly because they purpose to embark on diversification and maximization on their sources of income. A few of the farmers opted not to migrate, though they perceived climate alterations (the third cognitive situation), majorly as a result of the risk of uncertainties in the host zone or community (for example, cost of migration, employment guarantee) and favoruable socioeconomic situations in the home community or zone (for instance, education household size, land size). They were risk averse because of these conditions. The number four cognitive situation indicates that farmers were not aware and were still not aware of any alterations in climatic situations and may be satisfied with their economic situations, hence do not consider migration as choice that is profitable or they may be lacking the knowledge and skill required to migrate.

\subsection{Function of Socioeconomic Qualities in Migration as an adaptation measure}

A good comprehension of the socioeconomic attributes of farmers is crucial to recognition the major factors encouraging migrations. The decision taken by farmers to migrate constitutes strategies of the farm households which are mainly articulated for the purpose of overcoming the income loss and social deprivation risks and ensuring smoothing of consumption. For assessment of the function of socioeconomic situations or background as an adaptation strategy, a dichotomous (binary) logistic regression model was utilized with the migration option of farmers (migration $=1$ and non - migration $=$ 0 ) being a single categorical predictor. Socioeconomic qualities of the farm families including age of household head $(\mathrm{HH})$, formal education level of the farming $\mathrm{HH}$; proportion of males in the farm households to sum of household size; proportions of other members of the household (proportion of females and children below the age of 10years); farm land size; land ownership status (own farm land = 1 ; rent $=0$ ); and livestock ownership formed the independent variables. 
Table 2 indicates that age and educational status of $\mathrm{HH}$ head; proportion of male proportion of other members of the family, farm size and land ownership significantly drove decision to migrate during early and late farming seasons. The age of farming $\mathrm{HH}$ head positively contributed to choice of migration during both farming seasons. The age of the farming household head implies farming experience, which is a determinant of farmers' perception, adaptation decision and propensity to adapt. Older farmers have a high sense of felt need and responsibility to ensure that their families/households achieve sustained sources of livelihood, thus decide to migrate or advice other members of their households to migrate. The migration project is aimed at reducing dependence level and ensuring flow of remittances to the folks at home.

\section{Table 2: Function of socioeconomic attributes in migration as an adaptation}

\begin{tabular}{|lll|}
\hline Variables & $\begin{array}{l}\text { Migration in early cropping } \\
\text { season }\end{array}$ & $\begin{array}{l}\text { Migration in late farming } \\
\text { season }\end{array}$ \\
\hline Age $(\mathrm{HH}$ head) & $0.0504729(4.69) * \star$ & $0.080679(5.75) * *$ \\
\hline Education $(\mathrm{HH}$ head) & $0.1601680(5.12) * *$ & $0.1617110(4.47) * \star$ \\
\hline Farming size & $-0.689843(-2.10) *$ & $0.0515639(4.73) * \star$ \\
\hline Ownership status & $-0.689842(-2.63) *$ & $-0.7724287(-2.83) *$ \\
\hline Male proportion to HH size & $5.858990(5.22) * *$ & $7.243809(5.91) * *$ \\
\hline $\begin{array}{l}\text { Others' proportion to HH } \\
\text { size }\end{array}$ & $1.213610(8.65) * *$ & $1.770834(10.33) *$ \\
\hline Livestock ownership & $-0.027549(-0.20)$ & $0.018415(0.13)$ \\
\hline
\end{tabular}

${ }^{*} p<0.05 ; * * p<0.01$

Level of formal education positively influenced migration of farming $\mathrm{HH}$ heads through which enhancement of their capacity to access and articulate information relating to conditions of climate and give response. Farmers who have reasonable level of education have higher level of awareness with regards to available opportunities in their host communities or zone. There is also the ripple effect of education which encourages other members of the household to also embark on movement from the home zone or community. A higher proportion of males in the farm families positively affected the decision and plan to migrate. This is attributed to the fact that more male members of the households gives assurance of more hand in easing of income and more efficient in taking advantage of social networks in their host communities or zones. The proportion of women and children below the age of 10years implies dependence; hence, a higher proportion positively influences decisions to migrate in order to meet up with their income need for improved consumption desires. Land ownership pattern was significant, but the coefficient bore a negative sign, implying that farmers who rent farm land have more likelihood of migrating due to poor net income. The net income is what accrues to them after rent payment. This becomes insufficient while trying to meet up with consumption desires or needs, as well as 
other needed expenditures of the household in the home community. Farm size significantly, but negatively influence migration in both farming seasons. Tha et al., (2018) found that farm size only influenced decision to migrate in one of the farming seasons (Rubi) in India; that farm land is negatively significant implies that larger farm size requires greater family labour for farm operations; as a result, farming households may not have the intention to embark on migration or encourage any member to migrate.

\subsection{Function of migration in agricultural extension services}

The current context of climate change and its associated risks calls for frequent obtainance of new knowledge via adequate and time-precision extension services. Two institutional arrangements that enhance adaptation most include agricultural extension services and credit facilities (Jha et al., 2018). Delivery of information or messages on seasonal variations in climate and new innovations is facilitated by agricultural extension services to assist farmers in perceiving changes in climate change rapidly and guide them to adjust their agronomic practices to align with the alterations. Through migration, farmers have awareness through knowledge transfer and income generated from host community to home community for effective usage of extension services. Social networks are channels through which return migrants assist local communities to master the application of technology in farm operations and raise awareness level about institutional gains. Farmers access information related to climate including anticipated seasonal rainfall and temperature levels, timing of the onset of storm and forecasting extremes of climate in the form of flood and drought from climate extension sources in the Nigerian Meteorological Agency. Agricultural extension services of the Delta Agricultural and Rural Development Agency (DARDA) offer information on agricultural mechanization, improved crop varieties, drought tolerant varieties of crops, sources of quality seeds, plant protection methods, soil health management and market information. The Nigerian Meteorological Agency through its climate extension unit disseminates information using television, radio, mobile phone and internet. Agricultural extension sources include field officers, television, mobile phone and radio. Differences are indicated between the adoption behavior of migrated and non - migrated farmers during the two farming seasons studied (Figures 1 and 2).

Figure 1 and 2 are indicative of the higher usage of both climate and agricultural extension services among migrant farm families than non - migrant farm families. Most ( $70-76 \%)$ of the migrating farmers used radio. Radio is the oldest source of information to the u sage of newspapers. Most (60 $75 \%$ ) of the migrating farm families subscribe to adoption of information offered by Nigerian Meteorological Agency and extension field officers. Scheftran et al. (2012) observe that migrating farm families have better information and knowledge about usage of mobile phones and television in farm management as a result of the experiences they had through their involvement in social networks and experiences gained in their host communities. Ofluoku (2019) found that rural - rural migrant arable crop farmers were included and benefitted from agricultural extension services of their host communities. The usage of other extension sources, including newspapers and mobile phones is determined by the farmers' educational level. This is more so as mobile phone is one of the knowledge-based innovations. As a

Page 12/25 
result of their level of formal education, migrating farmers have become more proficient in the usage of these information resources for farm or agricultural management. Likewise, remittances received from host communities or zone create improvement in their economic well - being. This empowers them to procure and utilize mobile phones, computers, newspapers, televisions and radios in their home communities or zones. The information need of non - migrating farmers is capable of being met when migrating farmers share information, technology, knowledge and skills with them, thereby enhancing "social learning" and the capacity to adapt to climate change in the home communities or zones.

\subsection{Migration as an adaptation strategy}

The way migration promotes farmers' capacity to adapt and make possible adoption of other strategies is examined in this section. A total of 11 adaptation strategies, inclusive of migration were identified as being very suitable for farm management operations. These included planting improved varieties of crops, shifting from land under cultivation, controlled irrigation, adoption of soil and water conservation practices, crop insurance, migration, switching from farm to non-farm livelihood activities, leasing of land, cultivation of horticultural and vegetable crops. The farmers indicated their options of adaptation methods according to their perceptions about alterations in temperature and precipitation and their individual farming practices differently for early farming and late farming seasons.

\section{Table 3: Function of migration in promoting farmers adaptive capacity by cropping season}

\begin{tabular}{|c|c|c|c|c|c|}
\hline Household $(\mathrm{HH})$ adaptation & Adaptation le & & & & \\
\hline (Number of adaptation strategies) & $\begin{array}{l}\text { No adaption } \\
(0)\end{array}$ & $\begin{array}{l}\text { Low } \\
(1-3)\end{array}$ & $\begin{array}{l}\text { Medium } \\
(4-6)\end{array}$ & $\begin{array}{l}\text { High } \\
(7-11)\end{array}$ & Total \\
\hline \multicolumn{6}{|l|}{ Early farming season } \\
\hline Total No of HH (Temp) & $132(19)$ & $18(26)$ & $307(44)$ & $78(11)$ & $698(100)$ \\
\hline Migrating HH (Temp) & 0 & $15(03)$ & $288(92)$ & $62(79)$ & $496(71)$ \\
\hline Total No of HH (Rain) & $195(28)$ & $202(29)$ & $279(40)$ & $21(3)$ & $698(100)$ \\
\hline Migrating HH (Rain) & 0 & $165(82)$ & $257(92)$ & $17(81)$ & $439(63)$ \\
\hline Late farming season & $7(11)$ & $168(24)$ & $30(44)$ & $147(21)$ & $698(100)$ \\
\hline Total No of HH (Temp) & 0 & $89(53)$ & $249(81)$ & $137(93)$ & $475(68)$ \\
\hline Migrating HH (Temp) & $132(19)$ & $183(26)$ & $305(44)$ & $78(11)$ & $698(100)$ \\
\hline Total No of HH (Rain) & 0 & $174(95)$ & $253(83)$ & $69(88)$ & $496(71)$ \\
\hline Migrating HH (Rain) & & & & & \\
\hline
\end{tabular}

Their options of adaptation measures were considered to be propelled by climate parameters, though they were aimed to generate profit as pointed out by the farming family heads (Jha et al., 2018; 
Nhemachena and Hassan, 2007; Maddison, 2006). While assessing the farmers' options of adaptation strategies, the level of adaptation was developed on the basis of the number of adaptation methods adopted by the farmers (Bhattaet. al. 2016; Jha et al, 2018). The number of adaptation indicated by the farm family heads ranged a minimum of 0 (no adaptation) to 11 (maximum number of adaptation methods used by any of the farmers) (Jha et al., 2018). The mean number of adaptation strategies adopted by the farmers during the early farming season for perceived alterations in climate parameters temperature and rainfall was above 4 for both of the parameters. In the late farming season, the mean was about 5 for perceived alterations in temperature and precipitation. This is congruent with the findings of Jha et al., (2018).

Adaptive capacity according to Brooks and Adger (2005) is system - controlled and can modify its qualities or behavior to widen its range of coping under extant climate alteration or later climate situations. In accordance, this study is of the assumption that farmers who have higher adaptation level (range of coping) possess higher adaptive capacity (Jha et al., 2018). The capacity to adapt likewise represent the capacity index of the individual farmer to control the impacts of climate change at the farm level which is dependent on the skill, formal education status and the ability of the farm family head (Tarleton and Rainsey, 2008). Table 3 shows that among the 698 farmers used for the survey study, 19\% and $28 \%$ failed to adapt to alterations in temperature and precipitation during the early farming season respectively. In the late farming season, $11 \%$ and $19 \%$ did not carry adaptive effort to change in temperature and rainfall, respectively.

Most (63-71\% and $68-71 \%$ ) adopted migration as an adaptation strategy in early farming and late farming seasons, respectively. Slightly, more farm families opted to migrate during late farming season than in early farming season. This is because early farming season is highly labour intensive than late farming season and it involves a lot of farm operations, while late farming season is not labour intensive. Since there is no adequate amount of operations for all the household members, some of them opted to migrate during late farming season. Out - migration from a state to another align very much with alterations in the yield of rice (a crop favoured in the rain season) (Viswanathan and Kumar, 2015). The variation between the result of this study and that of Viswanathan and Kumar (2015) is attributed to the fact that while the data used by them was based on state level migration, this study is based on microlevel assessment of migration as an adaptation method and majorly utilized behavioural qualities of farmers that wrought with uncertainty and unpredictability. However, the results of this study are in consonance with those of Jha et al. (2018) who also based their study on micro - level assessment of migrations. During the early farming season, for alterations in temperature, $26 \%$ had low level adaptation and for precipitation, $29 \%$ had low level adaptation. In the same period, $44 \%$ had medium level adaptation to temperature and $40 \%$ had medium level adaptation to alterations in precipitation, while $11 \%$ had high level adaptation to changes in temperature and $3 \%$ to changes in precipitation. Likewise, in late farming season, for alterations in temperature, $4 \%$ had low level adaptation and $26 \%$ had low level adaptation for alterations in precipitation. In this same season, $44 \%$ had medium level adaptation for alterations in temperature and another $44 \%$ for changes in rainfall, while $21 \%$ had high level adaptation to changes in temperature and $11 \%$ for changes in rainfall. Therefore, medium level adaptation was dominant in the 
study area. This implies that farmers adopted $4-6$ distinct adaptations measures every season in reaction to alterations in temperature and precipitation.

During the early farming season, $71 \%$ migrated because of changes in temperature, while $63 \%$ embarked on migration because of changes in rainfall. In late early farming season, $68 \%$ migrated due to alterations in temperature, as $71 \%$ migrated as a result of alteration in precipitation. To evaluate the significance of migration in promotion of farmers' capacity to adapt to alterations in climate, by farming season, the proportion of migrating farmers to total households adopting climate change adaptation strategies at each level of adaptation was examined. In early cropping season, about $79-81 \%$ of farm families with high level of adaptation and about $92 \%$ of farmers that had medium level of adaptation were migrating farm families. Also, in late cropping season, $88-93 \%$ who had high level adaptation, $81-83 \%$ that had medium level adaptation were migrating farm families. These results are indicative of the fact that migrating farm families have a greater capacity to adapt to climate change since they have the ability and capability to adopt more adaptation strategies because of the support from host communities in the shape of remittances, social networks, knowledge and resources.

\subsection{Adaptation strategies adopted by migrating farm families by season in the study area}

In order to evaluate the significance of migration in adoption of other adaptation methods, separate analysis were done for migrating household and non - migrating households with respect to changes perceived in temperature and precipitation for early farming and late farming seasons. For both early and late farming season, their adaptation responses for alteration in temperature and rainfall were of the same trend (Figures 3a,b,c,d). Migrating farm families chose more adaptation strategies than non migrating families. For temperature and precipitation in early farming season $94-95 \%$ adopted irrigation; $43-70 \%$ chose to adopt changing land under cultivation, $51-58 \%$ adopted improved crop varieties that are bred to be resilient to prevailing climate in the scenario of climate change, $58-66 \%$ of the migrant farm families adopted crop insurance to avert risk of loss of crops, $24-28 \%$ chose to adopt water conservation, 14 - 18\% adopted soil conservation practices; $19-24 \%$ decided to move onto non farm livelihood activities by way of diversification, $38-44 \%$ planted vegetables and $15-20 \%$ opted for horticultural production. Likewise, in late farming season, $98-99 \%$ opted for irrigation, $91 \%$ chose to plant improved varieties of crops, about $71 \%$ change their farmland, $58-59 \%$ opted for crop insurance, $44-46 \%$ chose to practice soil conservation, $39-40 \%$ decided to cultivate vegetables, $23-25 \%$ practiced water conservation and about $19 \%$ diversified to non - farm livelihood activities among the migrating farm families for both temperature and precipitation. In comparison, both migrating families, the adoption score of non - migrating farm families that opted for these adaptation strategies was glaringly low. However, the common choice of adaptation strategies between migrating farmers and non - migrating farmers is planting of improved crop varieties, irrigation, crop insurance and soil conservation practices, water conservation and vegetable cultivation. The adaptation strategies are known to be intensive in nature in terms of resources, capital and knowledge. This makes the migrating households to a comparative advantage over non - migrating farm households. Migrating farm families had the benefit of remittances and knowledge acquired from host community or zone. Migrant farmers 
acquired knowledge of crops and soil and water conservation technology, the social network of the migrant in the host community.

Migrant farmers were quick to access and better informed about any new government agricultural development initiative, hence accessed the facilities in the schemes successfully. Remittances from migrants in host zones were utilized to buy farm inputs, especially seeds of improved varieties of crops. The remittances also helped them to procure and adopt modern or improved farm mechanization technologies. The study results imply that remittances social networks and knowledge acquired from host communities has direct positive influence on the progression and improvement migrating farm families' economic situation. However, to limited extent, non - migrating farm families also tap from the migrating households to promote their ability to adapt the innovations for adaptation to climate change. It is therefore, convenient to assert that the micro level, migration of farmers is capable of having beneficial outcomes for improvement of adaptation, sustainability of livelihood and resilience to climate change.

\section{Conclusion}

Climate - driven migration is considered as an adaptation strategy for the mitigation of adverse and extreme weather situations born out of alterations in climatic conditions. Farmers tend to often embark on migration to diversify their sources of income, as well as create smooth consumption. However, migration has a far broader function as a strategy for adaptation to climate change. This study assessed the effect farmers' perception of climate has on farm family migration. It also evaluated the contribution made by migration to promotion of farmers' capacity to adapt through scale up of their financial capabilities and acquisition of knowledge relative to improved agricultural technologies. As well, the influence wielded by migration in creation of access to climate and agricultural extension services was examined. In addition, variations in adaptation methods for early and late cropping seasons were explored to unveil the advanced cultivation practices that were better resilience to climate alteration. This study reveals that climate - driven livelihood risk is the main propeller of farm family migration during both farming seasons. Migration also offered economic incentives through employment opportunities and enhanced value placed crops in the home zone. The socioeconomic qualities of the farm family, such as household head's age, male proportion in the household and the ratio of dependency promotes sense of responsibility in favour of livelihood sources sustenance of the house, thus making positive contributions to migration of farmers. Formally educated farmers have a higher propensity to migrate as they are well abreast with opportunities and gains that are available outside their communities. However, land size negatively influenced migration of farmers. Land ownership is as well a crucial consideration in migration. Large farm size and land ownership promotes farm income, which consequently helps to achieve smooth consumption and other necessities.

Comparatively, marginal and smallholder farmers and tenant farmers possess a higher sense of insecurity, this higher propensity to migrate. While comparing migrant and non - migrant farmers, migrant farm families better accept to utilize instruction - based, knowledge - based, and technology - 
based climate and agricultural extension services from sources such as agricultural extension, field officers, meteorological agency, newspapers, television and radio. Migrating farm families most times have a higher adaptation score. They are also of superior capability for adoption of adaptation strategies that are intensive in terms of knowledge, capital and resources because of remittances coming from migrating members of the household. Non - migrating farm families only receive encouraging resources and knowledge from outside the communities through spillover from migrating families. In all, migrating farming households have advantage over non - migrating farming households with respect to adaptive capacity. For further study, not revenues of migrating farm families and that of non - migrating farm families should be examined by way of comparison, to further comprehend migration as an adaptation strategy against climate alterations.

As for policy perspectives, emphasis should be placed on creating a relationship between reduction of risk, human capacity building and development in rural communities. Efforts should be made by government to livelihood options that are not climate - driven to enable farm families diversify. In order to reach non - migrating farm families, training and workshops should be organized for this set of farmers so that they can handle knowledge - intensive adaptation strategies. This will help them to develop adaptive capacity. The policy of empowerment through farmers' groups should be sustained as this will enhance formation of social networks that will enhance adaptive capacities on non - migrant and migrant farmers.

\section{References}

Adger, W.N., Dessai, S., Goulden, M., Hulme, M., Lorenzoni, I., Nelson, D.R., Naess, L.O., Wolf, J. \&Wreford, A. (2009). Are there social limits to adaptation to climate change? Climate Change, 93(3), $335-354$.

Adger, W.N., Kelly, P.M., Winkels, Huy, L.Q. \& Locke, C. (2002).Migration, remittances, livelihood trajectories, and social resilience.AMBIO.A Journal of the Human Environment, 31(4), 358 - 366.

Ahmed, A.U., Hassan, S.R., Etzold, B. \&Neelormi, S. (2012). Where the rain falls case study: Bangladesh. Bonn: United Nations University and Institute for Environmental and Human Security.

Banerjee, S., Gerlitz, J.I. \&Hoermann, B. (2011).Labour migration as a response strategy to water hazards in the Hindu Kush-Himalayas. Kathmandu, Nepal: ICIMOD.

Barnett, J. \& Webber, M. (2009).Accommodating migration to promote adaptation to climate change. The Commission on Climate Change and Development. Available at: www.ccdcommixsion.org

Below, T. Artner, A., Siebert, R. \&Sieber, S. (2010). Micro-level practices to adapt to climate change for African small-scale farmers. A review of selected literature.Environment, Production and Technology Division. 
Bhatta, G.D. \&Aggarwal, P.K. (2016).Coping with weather adversity and adaptation to climatic variability: A cross - country study of smallholder farmers in South Asia.Climate and Development, 8(2), 145 - 157.

Bhatta, G.D. \&Aggarwal, P.K. (2016).Coping with weather adversity and adaptation to climatic variability: A cross-country study of smallholder farmers in South Asia. Climate and Development, 8(2), $145-157$.

Bhatta, G.D., Aggarwal, P.K., Kristjanson, P. \&Shrivastava, A.K. (2016).Climate and non-climate factors influencing changing agricultural practices across different rainfall regimes in South Asia.Current Science, 110 (7), 1272.

Bhatta, G.D., Aggarwal, P.K., Poudel, S. \&Belgrave, D.A. (2015a). Climate-induced migration in South Asia: Migration decisions and the gender dimensions of adverse climate events. Journal of Rural and Community Development, 10(4), 15 - 28.

Bhatta, G.D., Aggarwal, P.K., Shrivastava, A.K. \&Sproule, L. (2016). Is rainfall gradient a factor of livelihood diversification? Empirical evidence from around climate hotspots in Indo-Gangetic plains. Environment, Development and Sustainability, 18(6), 1657 - 1678.

Bryan, E.,Deressa, T.T., Gbetibouo, G.A. \&Ringler, C. (2009). Adaptation to climate change in Ethiopia and South Africa: Options and constrains. Environmental Science and Policy, (12(4), 413 - 426.

Conway, D. \& Cohen, J.H. (1998).Consequences of migration and remittances for Mexican transactional communities.Economic Geography, 74(1), 26 - 44.

deHaan, A., Brock, K. \&Coulibaly, N. (2002). Migration, livelihoods and institutions: Contrasting patterns of migration in Mali. Journal of Development Studies, 38(5), 37 - 58.

De Hass, H. (2010). Migration and development: A theoretical perspective. The International Migration review, 44(1), $227-264$.

Etzold, B., Ahmed, A.U., Hassan, S.R. \& Neclormi, S. (2014). Clouds gather in the sky, but no rain falls: Vulnerability to rainfall variability and food insecurity in northern Bangladesh and its effect on migration. Climate and Development, 6(18 - 27).

Fei, J.C.H. \& ranis, G. (1964).Development of the surplus economy. $1<$ wiol

Gbetibouo, G.A. (2009). Understanding farmers' perceptions and adaptations to climate change and variability: the case of the Limpopo basin, South Africa. International Food Policy Research Institute. 489, $10-21$.

Gray, C. \&Bilsborrow, R. (2013). Environmental Influences on human migration and rural Ecuador. Demography, 50(4), 1217 - 1241. 
Gray, C. \& Mueller, V. (2012).Drought and population mobility in rural Ethiopia. World Development, 40(1), $134-145$.

Grothmann, T. \&Patt, A. (2005). Adaptive capacity and human cognition: The process of individual adaptation to climate change. Global Environmental Change, 15(3), 199 - 213.

Hansen, J.W., Marx, S.M. \& Weber, E.U. (2004). The role of climate perceptions, expectations and forecasts in farmer decision making: The Argentine Pampas and South Florida. Final Report of IRI Seed Grant Project.

Harris, J.R. \&Tadaro, M.P. (1970). Migration, unemployment and development: A two-sector analysis. The American Economic Review, 60(1), 126 - 142.

Hassan, R. \&Nhemachena, C. (2008). Determinants of African farmers' strategies for adopting to climate change: Multinomial choice analysis. African Journal of Agricultural and Research Economics, 2(1), 83 104.

Hicks, J. (1932). The theory of wages. London: McMillan.

Hunter, L.M., Murray, S. \&Riosmena, F. (2013).Rainfall patterns and US migration from rural Mexico.International Migration Review, 47(4), 874 - 909.

Jha, C.K., Gupta, V., Chattopadhyay, U. \&Sreeraman, B.A. (2018). Migration as adaptation strategy to cope with climate change.A study of farmers' migration in rural India. International Journal of Climate Change Strategies and Management, 10(1), 121 - 141.

Kates, R.W. (2000). Cautionary tales: Adaptation and the global poor societal adaptation to climate variability and change. Armstvdam, Netherlands: Springer.

Kohli, H.S., Sharma, A. \&Sood, A. (2011). Asia 2050: Realizing the Asian Century. New Delhi: Sage Publications.

Kumark, K.K \&Viswanathan, B. (2012). Weather variability and agriculture: Implications for long and short-term migration in India. Centre for Development Economics, Dehi School o Economics.

Laczko, F. \&Aghazarm, C. (2009). Migration environment and climate change: Assessing the evidence. Geneva: International Organization for Migration.

Livigstone, D.N. (2000). Environmental determination.In Johnston, R.J., Gregory, D., Pratt, G. \& Watts, M. (Eds). The Dictionary of Human Geography, $4^{\text {th }}$ ed. (pp $\left.212-215\right)$. Oxford: Blackwell.

Lucas, R.E. (1997). Internal migration in developing countries. Handbook of Population and Family Economics, 1, $721-798$. 
Lybbert, T.J. \& Sumner, D.A. (2012). Agricultural technologies for climate change in developing countries: Policy options for innovation and technology diffusion. Food Policy, 37(1), 114 - 123.

Maddison, D. (2006). The perception of land adaptation to climate change in Africa. CEEPA Discussion Paper No. 10. Centre for Environmental Economics and Policy in Africa. University of Pretoria, Pretoria.

Marin, A. (2010). Riders under storms: Contributions of nomadic herders' observations to analyzing climate change in Mongolia. Global Environmental Change, 17(1), 47 - 58.

Marx, S.M., Welber, E.U., Orlove, B.S., Leiserowitz, A., Krantz, D.H., Roncoli, C. \& Phillips, J. (2007). Communication and mental processes: Experimental and analytic processing of uncertain climate information. Global Environmental Change, 17(1), 47 - 58.

McDowell, C. \&Haan, A.D. (1997). Migration and sustainable livelihood: A critical review of the literature. Working paper, Institute of Development Studies, University of Sussex.

McLeman, R. \&Smit, B. (2006).Migration as an adaptation to climate change. Climate Change, 76(1/2), 31 -53 .

Mueller, V., Gray, C. \&Kosec, K. (2014).Heat stress increase long-term human migration in rural Pakistan. Nature Climate Change, 4(3), 182 - 185.

Nhemachena, C. \& Hassan, R. (2007).Micro-level analysis of farmers' adaptation to climate change in Southern Africa. IFPRI Discussion Paper No. 00714, International Food Policy Research Institute, Washington D.C.

Ofuoku, A.U \&Chukwuji, C.O. (2012).Impact of rual-urban migration on plantation agriculture in the Niger Delta Region, Nigeria.Journal of Rural Social Sciences, 27(1), 6 -11.

Ofuoku, A.U. \& Albert, C.O. (2014).Conservation of traditional agricultural knowledge in Delta State, Nigeria.Social Change, 44(3), $401-411$.

Ofuoku, A.U. (2017). Contribution of rural-urban migrants' remittances to farming household food security, in Delta Central Agricultural Zone, Delta State, Nigeria. Journal of Agribusiness and Rural Development, 3(45), 655 - 663.

Ofuoku, A.U. (2019). Social inclusion of rural - rural migrant arable crop farmers and agricultural production in Delta State, Nigeria.Rural Society, 28(2), $144-160$.

Ofuoku, A.U., Okoh, R.N. \& Saiki, P.K. (2011). Determinants of adaptation to climate change among arable crop farmers in Edo State, Nigeria and its implications of extension service. Agriculture-Science and Practice Journal, 3(2), 3 - 4. 
Patnaik, U \& Das, P.K. (2017). Development interventions confer adaptive capacity? Insight from rural India.World Development, 97, 298 - 312.

Patnaik, U. \& Narayanan, K. (2015). How effective are coping mechanisms in securing livelihoods against climate aberrations? Evidence from rural India. International Journal of Climate Change Strategies and Management, 7(3), 359 - 374.

Porter, J.R., Xie, L., Challinor, A.J. Cochrane, K., Howden, S.M., Iqbal, M.M., Lobell, D.B. \&Travasso, M.I. (2014). Food security and food production systems. Cambridge: Cambridge University Press.

Rivera, W.M. \&Sulaiman, V.R. (2009). Extension: Object of reform, engine of innovation. Outlook on Agriculture, 38(3), $267-273$.

Roncoli, C., Ingram, K. \&Kirshen, P. (2002). Reading the rains: local knowledge and rainfall forecasting in Burkina Faso.Societies and Natural Resources, 15(5), 409 - 427.

Scheffran, J., Marmer, E. \& Sow, P. (2012). Migration as a contribution to resilience and innovation in climate adaptation: social networks and co-development in North West Africa. Applied Geography, 33, $119-127$.

Scheffran, J., Marmer, E. \& Sow, P. (2012). Migration as a contribution to resilience and innovation in climate adaptation: Social networks and co-development in Northwest Africa. Applied Geography, 33, 119 $-127$.

Scheffran, J., Marmer, E. \& Sow, P. (2012). Migration as a contribution to resilience and innovation in climate adaptation: Social networks and co-development in Northwest Africa. Applied Geography, 33, 119 $-127$.

Stark, O. \& Bloom, D.E. (1985).The ne economics of labour migration. The American Economic Review, 75(2), $173-178$.

Stark, O. \& Lucas, R.E. (1988).Migration, remittances, and the family.Economic Development and Cultural Change, 36(3), $465-481$.

Stark, O. (1984). Rural-to-urban migration in LDCs: A relative deprivation approach. Economic Development and Cultural Change, 33(3) $475-486$.

Stojanor, R., Kelman, I., Ullah, A.K.M., Duzi, B., Prochazka, D. \&Blahutova, K.K. (2016a). Local expert perceptions of migration as a climate change adaptation in Bangladesh.Sustainability, 8(12), 1223.

Stojanov, R., Duzi, B., Kelman, I., Nemec, D. \&Prochazka, D. (2016b). Local perceptions of climate change impacts and migration patterns in male, Maldives. The Geographical Journal, doi:10.1111/geoj.12177. 
Swanson, B.E. (2006). Extension strategies for poverty alleviation: Lessons from China and India. Journal of Agricultural Education and Extension, 12(4), 285 - 299.

Tacoli, C. (2009). Crisis or adaptation? Migration and climate change in a context of high mobility. Environment and Urbanization, 21(2), 513 - 525.

Tarleton, M. \& Ramsey, D. (2008). Farm - level adaptation to multiple risks: Climate change and other concerns. Journal of Rural and Community Development, 3(2), 51 - 68.

Taylor, E.J. (1999). The new economics of labour migration and the role of remittances in the migration process. International Migration (Geneva, Switzerland), 37(1), 63 - 88.

Tripathi, A. (2017). Socioeconomic backwardness and vulnerability to climate change: evidence from Uttar Pradesh State in India. Journal of Environmental Planning and Management, 60(2), 328 - 350.

Tsckakert, P. \& Tutu, R. (2010).Solastalgia: Environmentally induced distress and migration among Africa's poor due to climate change. Environment, forced migration and social vulnerability. Berlin: Springer.

Tyson, P.D., Lee-Thorp, J., Holmgren, K. \& Thackeray, J.F. (2002). Changing gradients of climate change in southern Africa during the past millennium: Implications for population movements. Climate Change, 52(1), $129-135$.

Upadhyay, H., Kelman, I., Lingaraj, G.T., Mishra, A., Shreve, C. \&Stojanov, R. (2015).Conceptualizing and Contextualizing research and policy for links between climate change and migration. International Journal of Climate Change Strategies and Management, 7(3), 394 - 417.

Viswanathan, B. \& Kumar, K.K. (2015). Weather, agriculture and rural migration: Evidence from state and district level migration in India. Environment and Economic Development, 20(4), 469 - 492.

Warner, K. \&Afifi, T. (2014). When rain falls: Evidence from eight countries on how vulnerable households use migration to manage the risk of rainfall variability and food security. Climate and Development, 6(1, 1 $-17$.

Warner, K. (2010). Global environmental change and migration: Governance challenges. Global Environmental Changes, 26(3), $402-413$.

Woodruff, C. \& Zenteno, R. (2007).Migration networks and microenterprises in Mexico. Journal of Development Economics, 8(3), 12-28.

\section{Figures}




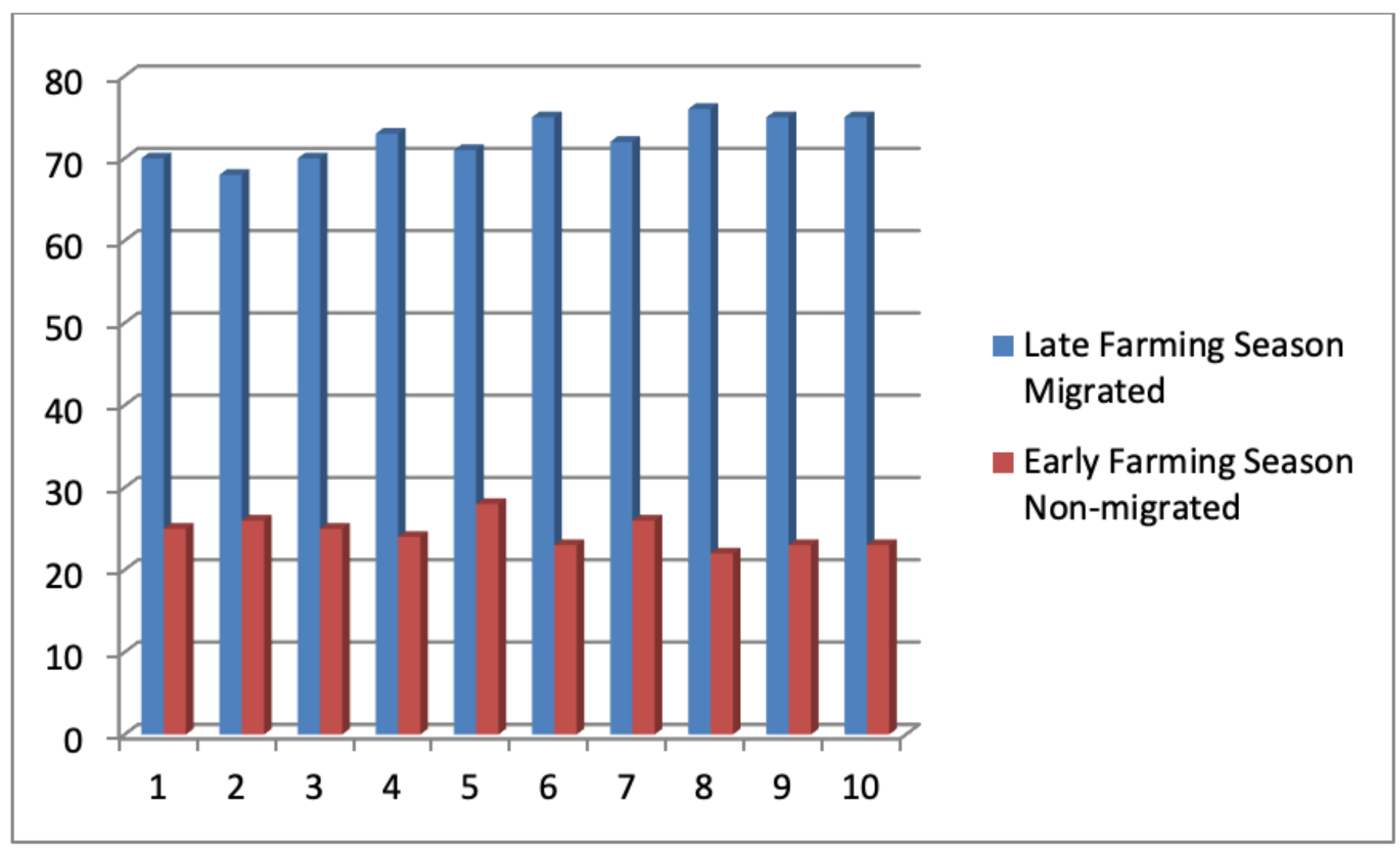

Figure 1

Choice of extension services. Early farming season 1. Agric. ext- newspapers; 2.Agric ext. mobile3. Agric Ext. radio; 4. Agric ext. TV.; 5. Agric. ext. field officer; 6. Clim. Ext. Met. Agency; 7.Clim. ext. mobile; 8. Clim. Ext. radio; 9. Clim. Ext. TV; 10. Clim. Ext. govt 


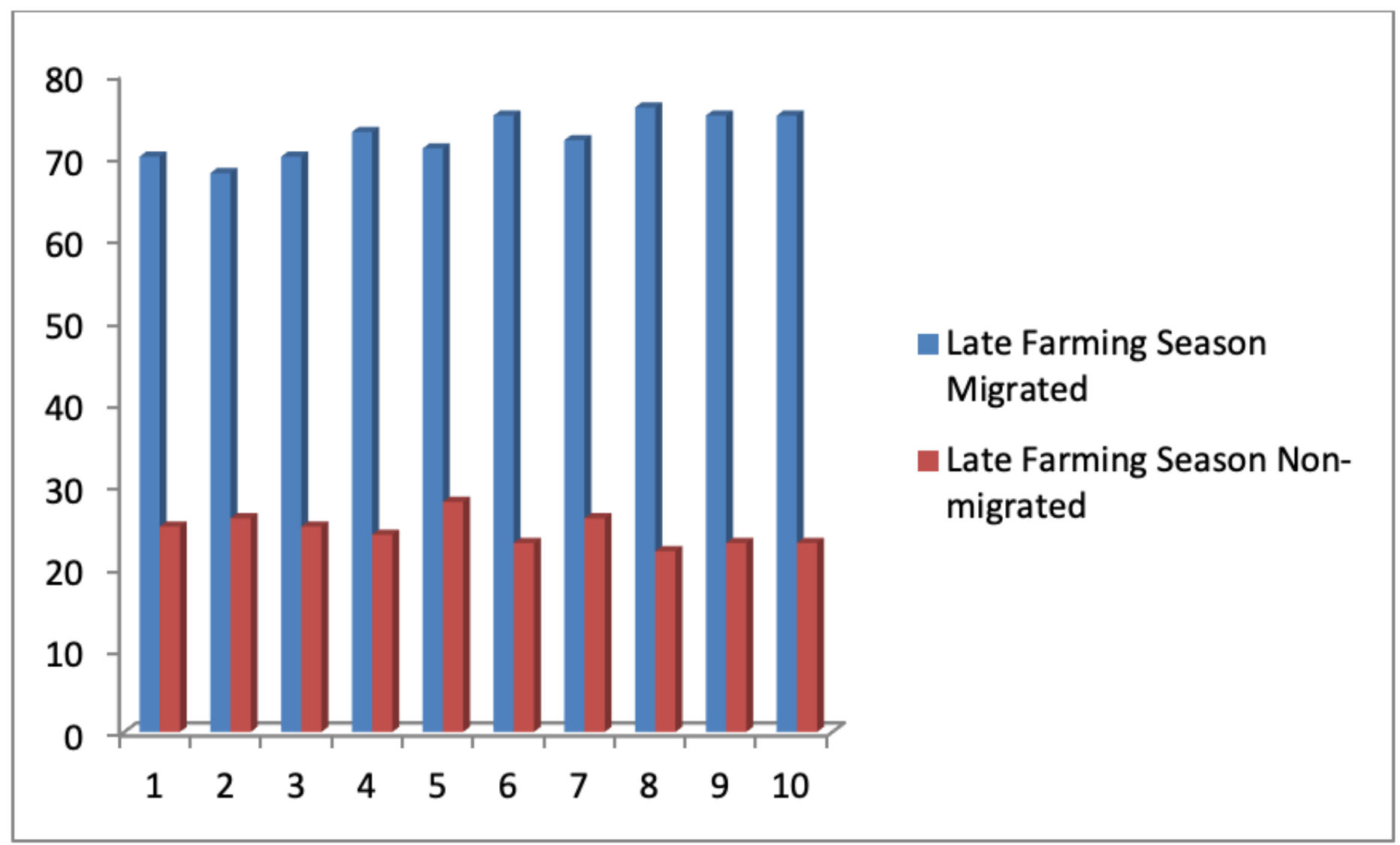

Figure 2

Choice of extension services. Late farming season 1. Agric. ext- newspapers; 2.Agric ext. mobile 3. Agric Ext. radio; 4. Agric ext. TV.; 5. Agric. ext. field officer; 6. Clim. Ext. Met. Agency; 7.Clim. ext. mobile; 8. Clim. Ext. radio; 9. Clim. Ext. TV; 10. Clim. Ext. govt 
$\mathbf{A}$

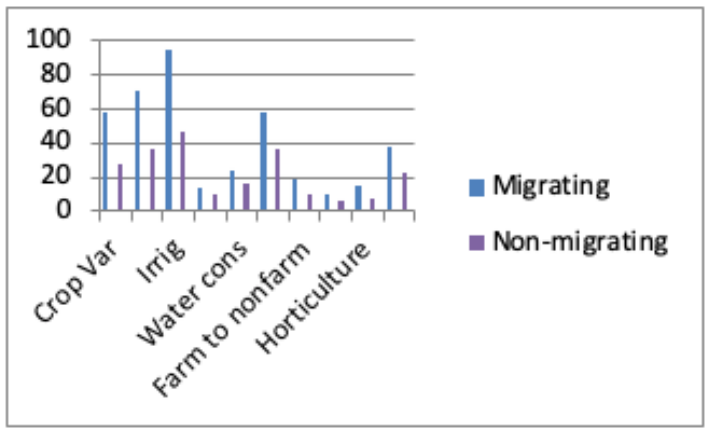

B

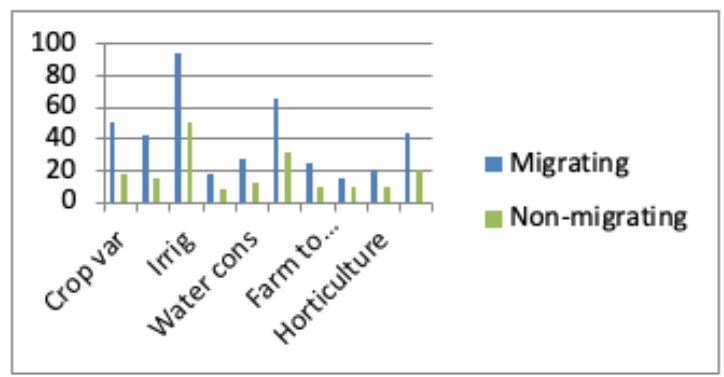

C

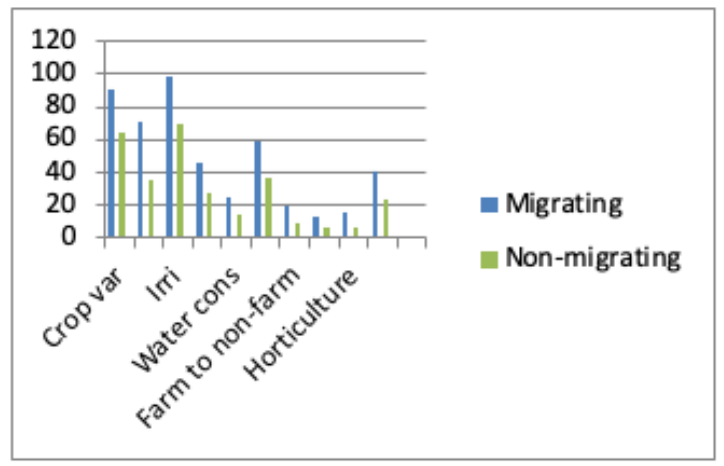

D

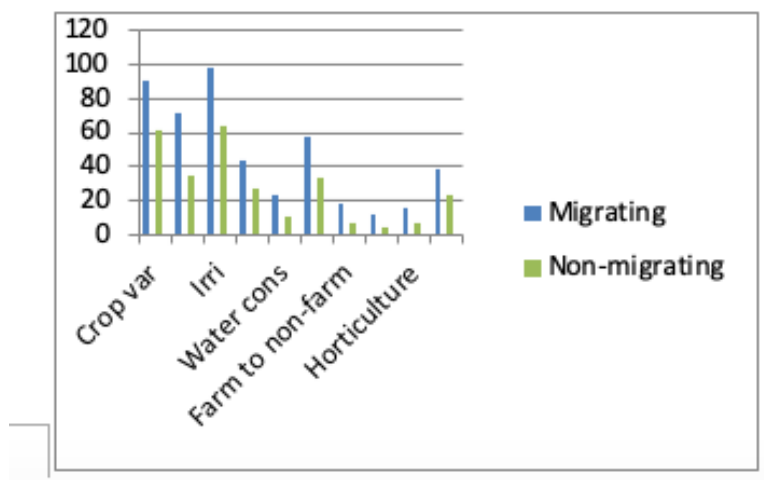

\section{Figure 3}

3a: Adaptation strategies (Early farming season -Temperature). 3b: Adaptation strategies (Early farming season - Rainfall). 3c: Adaptation strategies (Late farming season - Temperature). 3d: Adaptation strategies (Late farming season - Rainfall0 